\title{
Schistosoma mansoni among pre-school children in Musozi village, Ukerewe Island, North-Western-Tanzania: prevalence and associated risk factors
}

Deodatus M. Ruganuza ${ }^{1,3^{*}}$, Humphrey D. Mazigo', Rebecca Waihenya², Domenica Morona' and Gerald M. Mkoji ${ }^{4}$

\begin{abstract}
Background: Recent evidence indicates that pre-school children (PSC) living in S. mansoni highly endemic areas are at similar risk of schistosomiasis infection and morbidity as their school aged siblings. Recognizing this fact, the World Health Organization (WHO) is considering including this age group in highly endemic areas in control programmes using mass drug administration (MDA). However, detailed epidemiological information on S. mansoni infection among PSC is lacking for many endemic areas, specifically in Tanzania. This study was conducted to determine the prevalence of S. mansoni infection and its associated risk factors among PSC in Ukerewe Island, North-Western Tanzania.

Methods: This was a cross-sectional study, which studied 400 PSC aged 1-6 years. The Kato-Katz (K-K) technique and the point of care circulating cathodic antigen (CCA) immunodiagnostic test were used to diagnose S. mansoni infection in stool and urine samples respectively. A pre-tested questionnaire was used to collect demographic data and water contact behaviour of the children from their parents/guardians.

Results: Based on the K-K technique, $44.4 \%$ (95 \% Cl: 39.4-49.4) pre-school children were infected with S. mansoni and the overall geometric mean eggs per gram of faeces (GM-epg) was 110.6 epg with 38.2 and $14.7 \%$ having moderate and heavy intensity infections respectively. Based on the CCA, $80.1 \%$, (95 \% Cl: 76.0-84.0) were infected if a trace was considered positive, and $45.9 \%$, (95 \% Cl: 40.9-50.9), were infected if a trace was considered negative. Reported history of lake visits ( $\mathrm{AOR}=2.31,95 \% \mathrm{Cl}: 1.06-5.01, P<0.03)$ and the proximity to the lake shore $(<500 \mathrm{~m})$ $(\mathrm{AOR}=2.09,95 \% \mathrm{Cl}: 1.05-4.14, P<0.03)$ were significantly associated with $\mathrm{S}$. mansoni infection. Reported lake visit frequency (4-7 days/week) was associated with heavy intensities of $S$. mansoni infection $(P<0.00)$.

Conclusion: The prevalence of $S$. mansoni infection in the study population using K-K and CCA-trace-negative was moderate. The frequency of lake visits and the proximity to the lake shore were associated with the infection of $S$. mansoni and its intensity. These findings call for the need to include the PSC in MDA programmes, public health education and provision of safe water for bathing.
\end{abstract}

Keywords: S. mansoni prevalence, Intensity of infection, Pre-school children, Tanzania

\footnotetext{
*Correspondence: deorugz@gmail.com

'Department of Medical Parasitology and Entomology, School of Medicine,

Catholic University of Health and Allied Sciences, P.O. Box 1464, Mwanza,

Tanzania

${ }^{3}$ Institute of Tropical Medicine and Infectious Diseases (ITROMID), Jomo

Kenyatta University of Agriculture and Technology, P.O. Box 62000-00200,

Nairobi, Kenya

Full list of author information is available at the end of the article
}

C Biomed Central

(c) 2015 Ruganuza et al. This is an Open Access article distributed under the terms of the Creative Commons Attribution License (http://creativecommons.org/licenses/by/4.0), which permits unrestricted use, distribution, and reproduction in any medium, provided the original work is properly credited. The Creative Commons Public Domain Dedication waiver (http:// creativecommons.org/publicdomain/zero/1.0/) applies to the data made available in this article, unless otherwise stated. 


\section{Background}

Schistosomiasis remains a serious public health concern in sub-Saharan Africa and approximately one-third of the 192 million cases of schistosomiasis in the region are caused by Schistosoma mansoni, the causal agent of intestinal schistosomiasis [1]. An estimated 4.4 million people infected with S. mansoni have bloody diarrhoea and another 8.5 million have hepatomegaly associated with periportal liver fibrosis, portal hypertension and haematemesis [2]. Furthermore, complications of oesophageal varices and haematemesis supposedly result into 130,000 annual deaths [2, 3]. Among the school-going children, a chronic infection with $S$. mansoni contributes towards anaemia, stunted growth, organomegaly and poor cognitive functions; the combination of these morbidities may affect their future life $[4,5]$.

In Tanzania, studies on S. mansoni have been carried out mostly in school children where the prevalence of $S$. mansoni infection ranges from 32 to $64 \%$ and varies from one geographical area to another [6-8], furthermore $46 \%$ lack access to potable water, limiting the use to drinking where available, $87 \%$ lack improved sanitation and $16 \%$ practice open defaecation [9]. In the nearby East African countries the prevalence of $S$. mansoni in preschool children (PSC) was 44.3 and $16 \%$ respectively on the shores of Lake Albert and Lake Victoria in Uganda [10] and 14\% in Lake Victoria in Kenya [11]. Although intestinal schistosomiasis has been known to infect PSC since the early 1950's [12, $13]$, it is only recently that attention has focused on this particular group [10, 14-20]. For a long time, this age group was considered to be at low risk of severe infection [21]. However, given that the Kato-Katz technique, used for many years in epidemiological surveys of S. mansoni infection, has a low sensitivity for infection detection, the prevalence of infection among PSC may have been grossly under-estimated [22-25]. This could have resulted in the exclusion of the age group in the control programmes. It has been suggested that supplementing the Kato-Katz technique with diagnostic techniques that have a greater sensitivity such as the Circulating Cathodic Antigen test (CCA) (Sensitivity between 76.7 and $99.1 \%$, Specificity of $74.2 \%$ ), could improve the detection of infections in PSC [22-31]. As a matter of fact, a higher prevalence was recorded among school children in other endemic areas in sub-Saharan Africa when the CCA immunodiagnostic test was used alongside the Kato-Katz test [10, 11, 32]. However, ambiguity remains for the interpretation of CCA results where the traces in the test band can be considered either negative or positive, affecting the sensitivity of the test [33]. One study has shown a good sensitivity and specificity when traces are considered negative, but specificity is poorer when traces are considered positive [34]. It has been shown that CCA is not affected by S.haematobium [35] or Soil-transmitted helminths [36], while on the other hand Lewis-X trisaccharide epitopes can be picked up contributing to false positives [34]. The CCA test was used in the present study in addition to the Kato-Katz test.
Even where schistosomiasis has been investigated among PSC, very little is known about the risk factors associated with the disease in this age group. However, it has been observed that PSC can be exposed to infection when they accompany their parents/guardians or their older siblings to transmission sites [20]. Among the older children, risk factors often associated with schistosomiasis include the distance of households from the water contact points, the involvement in fishing or farming activities, gender and socio-economic status [15, 17, 18, 20, 37].

Although the World Health Organization (WHO) has acknowledged the need to include pre-school aged children in schistosomiasis control programmes, the epidemiological information on schistosomiasis among PSC remains scanty for many endemic areas, including Tanzania, where $51 \%$ of the population is at risk of being infected [38]. The aim of the present study was to determine the prevalence and intensity of S. mansoni infection among PSC, aged 1 to 6 years (12-83 months) in an endemic area, the Musozi village on the Ukerewe Island, in North-Western Tanzania and to identify the risk factors associated with the infection.

\section{Methods}

\section{Study area and population}

Musozi village is located on the main Island of Nansio, in Ukerewe district, Mwanza Region, at approximately $2^{\circ}$ $\mathrm{S}$ and $33^{\circ} \mathrm{E}$ in the North-Eastern part of the island, and at an altitude of $1100 \mathrm{~m}$ above sea level (Fig. 1). The climate is tropical and temperatures typically range from 17 to $27{ }^{\circ} \mathrm{C}$ with a mean annual rainfall of $1090 \mathrm{~mm}$. The area experiences two rainy seasons (a short rainy season between October and January, followed by a short dry spell from mid-January to February), and a long rainy season from March and June. According to the most recent census, the village has 712 PSC aged from 1 to 6 years (12 to 83 months) [39].

\section{Study design, inclusion and exclusion criteria}

This was a cross-sectional study of 400 systematically selected PSC aged 1-6 years (12-83 months), who had lived in the study village for at least 6 months before the study began and who had no history of having been treated with Praziquantel (PZQ) in the previous 1 year. A written consent was obtained from parents/guardians of the children, prior to their enrolment into the study.

\section{Data collection}

\section{Questionnaire}

A structured questionnaire was administered to the PSC's parents or guardians, the questionnaires collected information on the demographic characteristics of the PSC and their parents' demographic characteristics and water contact behaviour as a proxy for their children's risk of water contact. Water contact behaviour was assessed by inquiring on history of water contact i.e. whether the child has ever been to the lake and has had previous contact with 


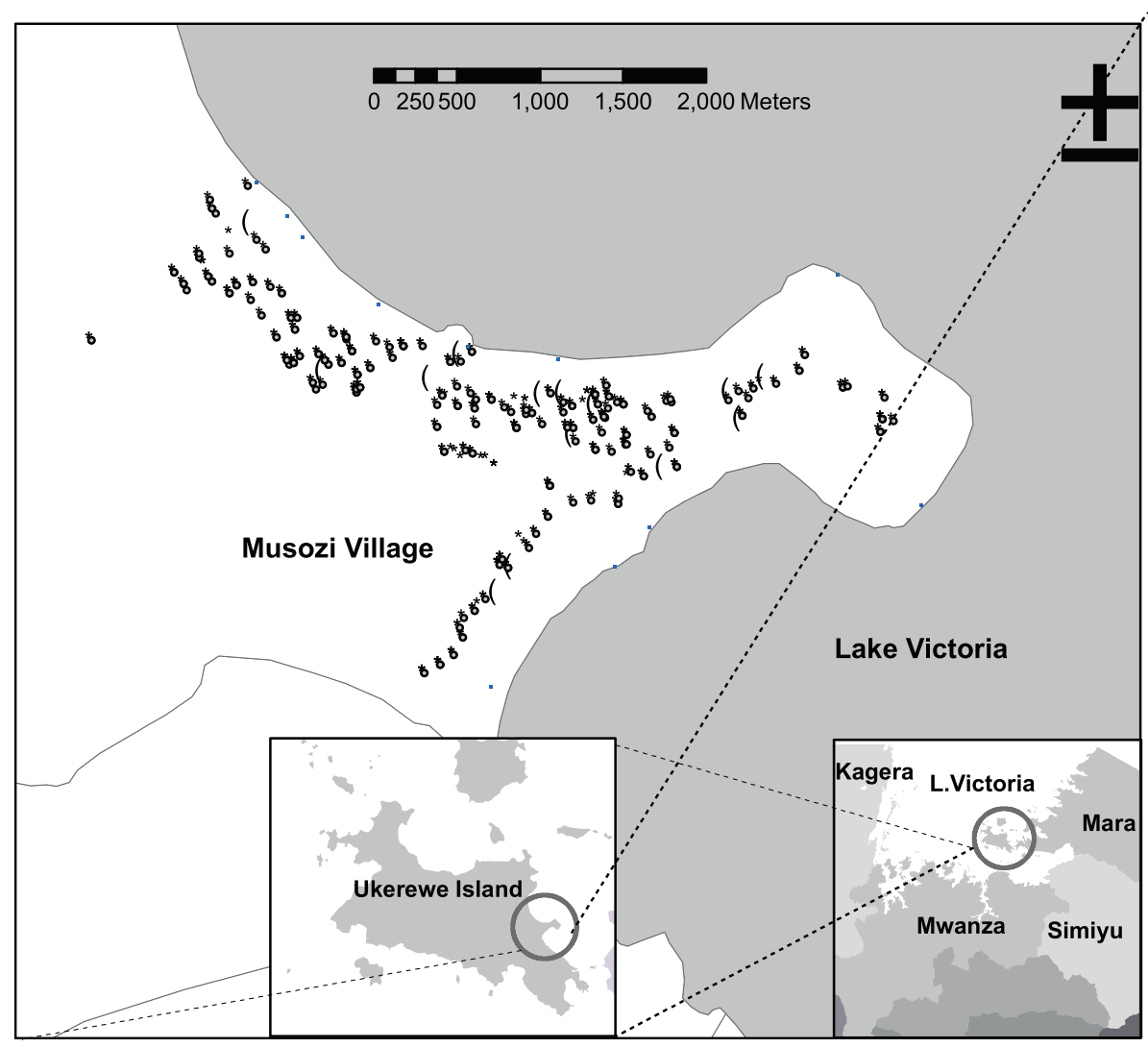

\section{Legend}

- Pre-school children with S.mansoni infection (CCAt+ and K-K)

( Boreholes and Well water (Drinking)

Lake waterpoints (Bathing and other domestic uses)

* households( of study participants)

Fig. 1 Map of Musozi village showing households of pre-school children, wells and lake water contact points

lake water, Mode of contact i.e. whether the child goes alone, with sibling or with parents/guardian, frequency i.e. the reported number of days in the last week that the child has been to the lake.

\section{Mapping of the household, lake water points and wells/ boreholes}

Global positioning system (GPS) data was taken for the study participant household, the closest Lake water contact point (where the household members bathe and fetch water for other domestic uses) and Well water point were taken by using a Garmin etrex handheld GPS receiver (Trimble Navigation, Sunnyvale, CA, USA). Data was recorded on data sheets and was later entered into Microsoft excel 2010 and then ArcGIS ArcMap 10.2.2 were analysis was done to obtain the distance from each household and its nearest lake water contact point. Distance data were taken to Stata for further analysis and the map of the study site was generated.

\section{Parasitological examination of stool samples}

Single stool and urine samples were collected in separate clean containers from each of the enrolled children. From each stool sample two Kato-Katz thick smears were prepared using a template that can hold $41.7 \mathrm{mg}$ of stool sample, supplied by Vestergaard Frandsen (Lausanne, Switzerland), according to a standard protocol [23, 40, 41]. The slides were left for $24 \mathrm{~h}$ for them to clear for easy visualization of S. mansoni eggs. After $24 \mathrm{~h}$, the smears were examined for eggs of $S$. mansoni and other helminths. Two independent and experienced parasitologists examined each slide. For each slide, characteristic eggs of $S$. mansoni that were present were noted by examiners. 


\section{Qualitative examination of CCA for S. mansoni in urine samples}

In addition to examining Kato-Katz stool smears by microscopy, urine samples were also collected from the enrolled study children and were tested for S. mansoni Circulating Cathodic Antigens (CCA) using the CCA Urine Cassette assay (Rapid Medical Diagnostics, Pretoria, South Africa) [42]. The preparation and examination of the urine samples were performed according to the manufacturer's instructions [42]. The results of the test were read 20 min after adding the buffer. If the control bands did not develop, the result was regarded as invalid. Because there is ambiguity in the interpretation of 'trace' in a CCA test band i.e. it can be read as positive or negative [33], we used two categories for diagnostic analysis in which valid results were either scored as trace positive or trace negative.

\section{Ethical considerations}

This study was approved by the Kenya Medical Research Institute (KEMRI) Scientific and Ethics Committee (SSC No. 2739) and by the Joint Institutional Review Board of the Catholic University of Health and Allied Sciences (CUHAS) and Bugando Medical Centre, Mwanza, Tanzania (review and publication certificate number: BREC No. 035/2013). Prior to recruiting the study participants, village meetings were held with parents and guardians, under the guidance of village leaders to explain the objectives of the study and the procedure to be used for data collection. Written informed consent was obtained from the parents/guardians of children before their enrolment into the study. Stool and urine collection are routine procedures and do not pose any risks to the study children. Praziquantel and albendazole at the recommended doses were administered to the infected children under the supervision of a qualified clinician. All the information obtained from the children and their parents was treated as private and confidential and the records were stored in a locked cabinet and data were entered in a password protected file in a computer.

\section{Data analysis}

The data entered and stored in Microsoft Excel 2007 was checked for entry errors and was analysed using statistical tools available in the STATA version 12 software (STATA Corp, College Station, Texas, USA). The age variable was described as mean \pm standard deviation and categorized into age groups: $1-<2,2-<3,3-<4,4-<5,5-<6,6-<$ 7 years. Binary variables were compared using the Chisquare test $\left(\chi^{2}\right)$ or the Fisher exact test, where appropriate. The intensity of infection was categorized according to WHO criteria as $\leq 99$ epg (light), 100-399 epg (moderate), or $\geq 400$ epg (heavy) $[43,44]$. Prevalence of infection was of $<10 \%$ is low, $\geq 10$ but $<50 \%$ is moderate prevalence and $>50 \%$ high prevalence. ANOVA or t-tests were used to test for the difference in mean egg counts for S. mansoni between sex and age-groups.

Demographic and socio-economic variables were assessed using logistic regression. The potential associations were first assessed at a bivariate level; then, factors with a $P$-value $<0.2$ were entered into the multivariate model. Sex and age group term were entered as a priori into the multivariate model. Stepwise backward logistic regression was used to determine whether these variables were independent factors of S. mansoni. Independent risk factors of faecal egg counts were identified in a linear regression model using a log-transformed egg per gram of faeces (epg) as outcomes variable and social demographic factors as explanatory variables. The odd ratios of each of the risk factors associated with faecal egg counts were obtained by taking the antilogarithm of the regression coefficient.

\section{Results}

\section{Demographic characteristics of the study children and} prevalence of $S$. mansoni infection

A total of 400 PSC aged 1-6 years (12-83 months) were enrolled into the study. Of these children, $49.2 \%(N=$ 197) were female and $50.7 \%(N=203)$ were males. The mean age of the children was $3.82 \pm 1.6$ years. Table 1 shows the age and sex distribution of the children.

\section{Prevalence of S. mansoni based on the Kato-Katz technique}

Based on the Kato-Katz stool smear results, a total of 170/383 children, 44.4 \%, (95 \% CI: 39.4-49.4) were found to be infected with S. mansoni, with a prevalence in males being $46.2 \%$ (90/195), (95 \% CI: 39.0-53.2), and in females $42.6 \%$ (80/188), (95 \% CI: 39.4-49.7). No gender-related difference in prevalence was observed $\left(\chi^{2}\right.$ $=0.50, P<0.48)$. The prevalence of infection increased with age $\left(\chi^{2}=61.8, P<0.00\right)$, with the youngest age group, $1-<2$ years, exhibiting a moderate prevalence of $16.9 \%$ and the much older age group, $6-<7$ years, a high prevalence of $72.7 \%$. The prevalence of infection

Table 1 Demographic characteristics of 400 pre-school children from Musozi village, in Ukerewe district, north-Western Tanzania

\begin{tabular}{lllll}
\hline Age (years) & Males & $\%$ & Females & $\%$ \\
\hline $1-<2$ & 26 & 12.81 & 37 & 18.78 \\
$2-<3$ & 36 & 17.73 & 41 & 21.81 \\
$3-<4$ & 42 & 20.69 & 28 & 14.21 \\
$4-<5$ & 30 & 14.78 & 31 & 15.74 \\
$5-<6$ & 39 & 19.21 & 35 & 17.77 \\
$6-<7$ & 30 & 14.78 & 25 & 12.69 \\
Total & 203 & & 197 & \\
\hline
\end{tabular}


was highest $(>50 \%)$ in the age group $4-<5$ years. The prevalence of $S$. mansoni infection based on the KatoKatz stool smear results stratified by age and sex is shown in Fig. 2.

\section{Prevalence of S. mansoni based on Circulating Cathodic Antigen (CCA)}

The prevalence of $S$. mansoni infection based on Point of Care-Circulating Cathodic Antigen Urine (POC-CCA) cassette tests, stratified by age and sex, is shown in Fig. 3. With regards to the POC-CCA, considering a trace as a positive result (CCAt+), 309/386, $80.1 \%$ (95 \% CI: 76.084.0) of the PSC were infected with S. mansoni. Stratified by age, the prevalence of $S$. mansoni in male children was $80.9 \%$ (95 \% CI: 75.3-85.3), while the prevalence for females was $79.1 \%$ (95 \% CI: 73.3-85.0). Stratified by age, the prevalence of $S$. mansoni (CCAt + ) was 69.3, 64.5, 76.1, 93.0, 87.0 and $96.0 \%$ for age groups $1-<2,2-<3,3-<4$, $4-<5,5-<6,6-<7$ years respectively. Considering a trace as a negative result (CCAt-), 177 out of 386 were found positive for $S$. mansoni infection and the prevalence was 45.9 \% (95 \% CI: 40.9-50.9). The prevalence of S. mansoni in male children was $48.2 \%$ (95\% CI: 41.2-51.2) while the prevalence in female children was $43.3 \%$ (95 \% CI: 36.2-50.5). Stratified by age, the prevalence of $S$. mansoni was $21.0,18.4,38.8,57.9,69.6$ and $78.2 \%$ for age groups $1-<2,2-<3,3-<4,4-<5,5-<6,6-<7$ years respectively.

Overall prevalence of S. mansoni based on Kato-Katz technique and circulating cathodic antigen combined The overall prevalence of $S$. mansoni infection based on the combined results of Kato-Katz technique and CCAt + was
$82.1 \%$ (95 \% CI: 78.2-86.0). The prevalence of S. mansoni infection did not vary by sex $\left(\chi^{2}=0.12, P<0.72\right)$, with male and females having a prevalence of 82.8 and $81.4 \%$ respectively. However, in relation to age, there was a significant difference in the prevalence of $S$. mansoni infection $\left(\chi^{2}=32.3, P<0.00\right)$ with the youngest age group having a prevalence of $69.5 \%$ and the older age group having a prevalence of $96.4 \%$.

\section{Intensity of S. mansoni infection}

The distribution of intensity of $S$. mansoni infection by age and sex is shown in Table 2 and The intensity category of $S$. mansoni infection is shown in Fig. 4. The overall geometric mean egg per gram of faeces (GM-epg) for the study participants was $110.61 \mathrm{GM}$-epg (95 \% CI: 93.1131.4). Male children had a higher GM-epg, 119epg (95\% CI: 93.7-150.8) than female children 102 epg (95\% CI: 79.2-131.4). However, the difference observed did not reach significance $(\mathrm{t}=0.83, P=0.79)$. The GM-epg was observed to increase with age, the older age group had the highest GM-epg $(\mathrm{F}=6.38, P<0.00)$. Of the 170 children with detectable $S$. mansoni eggs, 47.1, 38.2 and $14.7 \%$ had light, moderate and heavy infections respectively, as defined by WHO [44].

\section{Factors associated with S. mansoni infection in pre-school children}

The association between the prevalence of S. mansoni infection and demographic characteristics, water contact patterns and distance from the lake water contact point are shown in Table 3. Age $(P<0.01)$, history of going to the lake $(P<0.01)$, mode of contact $(P<0.01)$, frequency
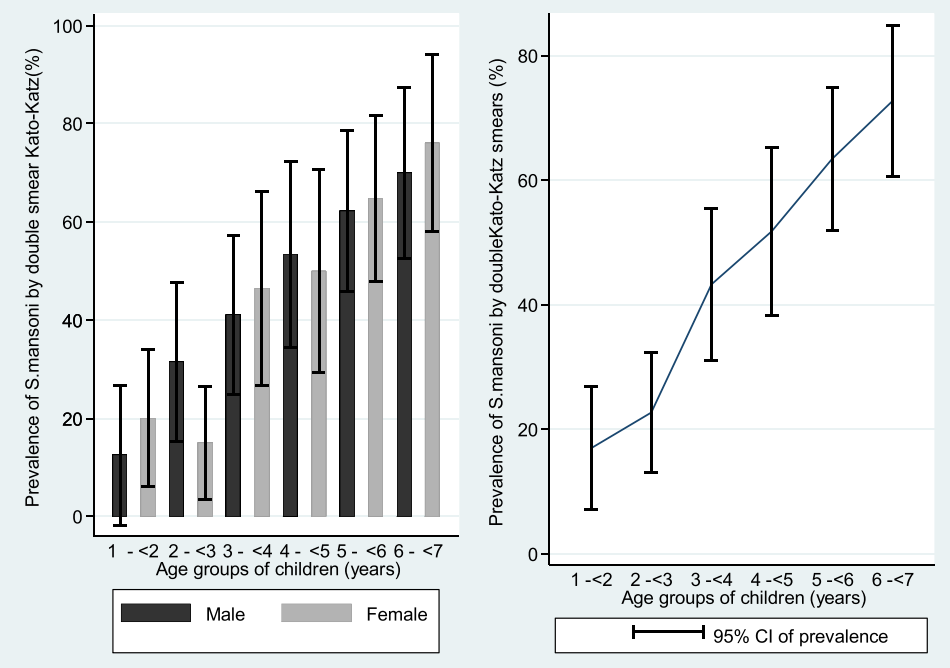

Fig. 2 Prevalence of S. mansoni based on Kato Katz technique among 383 pre-school children of Musozi villages, north-western Tanzania, stratified by sex and age 

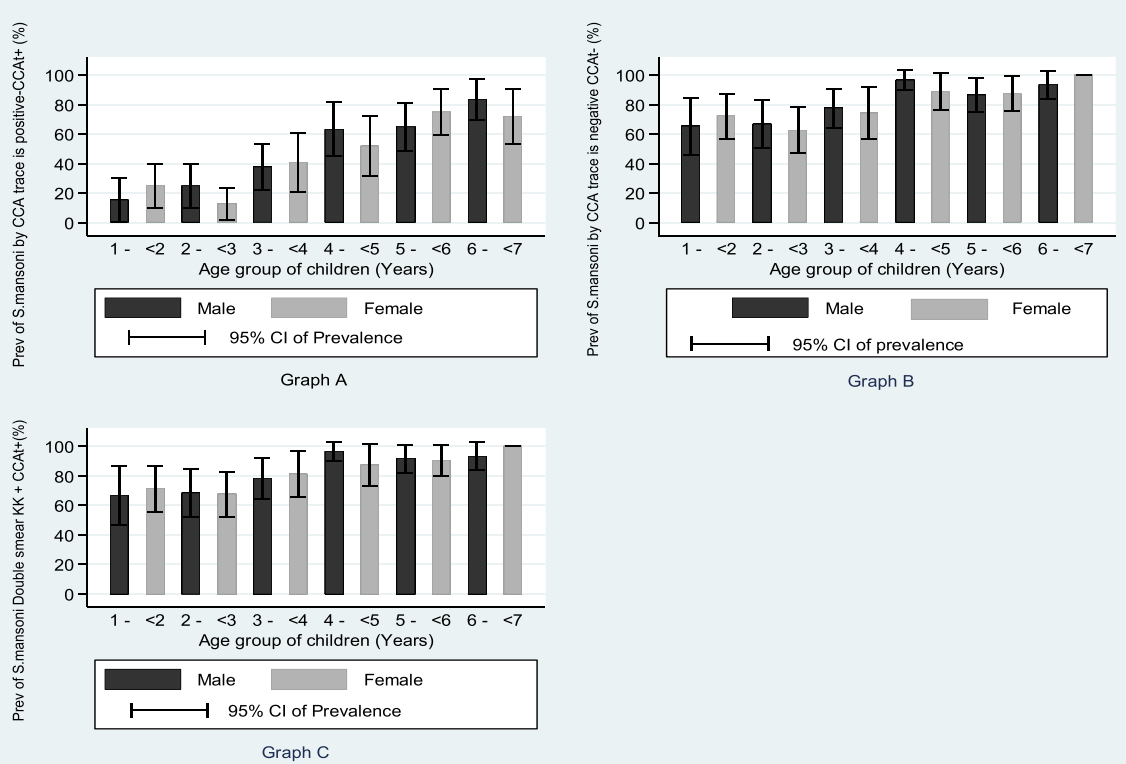

Fig. 3 Prevalence of S. mansoni based on circulating cathodic antigen, a: not including trace and $\mathbf{b}$ : including trace and c: combined Kato Katz and CCA trace positive among 383 pre-school children of Musozi villages, north-western Tanzania, stratified by age

of lake visits $(P<0.01)$ were significantly associated with $S$. mansoni infection.

Independent factors associated with the prevalence of infection are shown in Table 4. In a multivariate model, history of going to the lake (AOR $=2.13,95 \% \mathrm{CI}$ : $1.06-5.01$, $P<0.03)$ and living at a distance of less than $500 \mathrm{~m}$ from the lake water contact point $(\mathrm{AOR}=2.09,95 \% \mathrm{CI}$ : 1.05-4.14, $P<0.03$ ) were associated with the infection with $S$. mansoni.

The association between the intensity of S. mansoni infection, demographic characteristics, water contact patterns and distance from the lake water contact is shown in Table 5. Age $(P<0.00)$, history of going to the lake $(P<0.00)$, mode of contact $(P<0.00)$ and frequency of lake visits $(P<0.00)$ were significantly associated with $S$. mansoni infection.

The independent factors associated with logtransformed egg counts of $S$. mansoni are shown in Table 6. In a multivariate model, high frequency (4-7 days per week) of going to the lake $(\mathrm{OR}=1.84,1.18-$
2.86, $P<0.00)$ remained associated with a heavy intensity of infection.

\section{Spatial distribution of S. mansoni infection, wells and lake} water contact points

The map of Musozi village showing the households of where PSC live showing distribution of S.mansoni infection, the lake water and well water contact points is shown in Fig. 1 . The village has 12 boreholes/wells that are evenly distributed providing village members with easy access to well water; however, the water is used solely for drinking. The village also has 11 lake water contact points $(S$. mansoni infection sources) used to fetch water for other domestic needs including bathing.

\section{Discussion}

In the present study area, it appears that S. mansoni infection starts at an early age and is associated with various risk factors. This adds to the growing body of evidence that PSC can have schistosomiasis. The

Table 2 The distribution between the geometric mean intensity of infection in preschool children with S.mansoni infection in Musozi village by age and sex

\begin{tabular}{lllllll}
\hline Age category (years) & Male GMI (epg) & $95 \% \mathrm{Cl}$ & Female GMl (epg) & $95 \% \mathrm{Cl}$ & Combined GMl (epg) & $95 \% \mathrm{Cl}$ \\
\hline $1-<2$ & 283.9 & $25.5-2122.8$ & 45.8 & $15.8-134.8$ & 74.7 & $29.7-189.6$ \\
$2-<3$ & 94.9 & $39.3-228.9$ & 46.0 & $10.8-195.5$ & 73.5 & $39.9-146.4$ \\
$3-<4$ & 96.9 & $58.5-160.4$ & 62.4 & $33.6-115.5$ & 79.5 & $54.6-115.8$ \\
$4-<5$ & 85.2 & $46.2-157.2$ & 100.8 & $51.5-197.2$ & 90.9 & $60.1-140.4$ \\
$5-<6$ & 148.7 & $94.5-234$ & 209.5 & $133.9-327.6$ & 175.8 & $128.9-239.7$ \\
$6-<7$ & 143.3 & $80.5-255$ & 108.0 & $71.7-162.7$ & 125.3 & $88.6-117.2$ \\
\hline
\end{tabular}




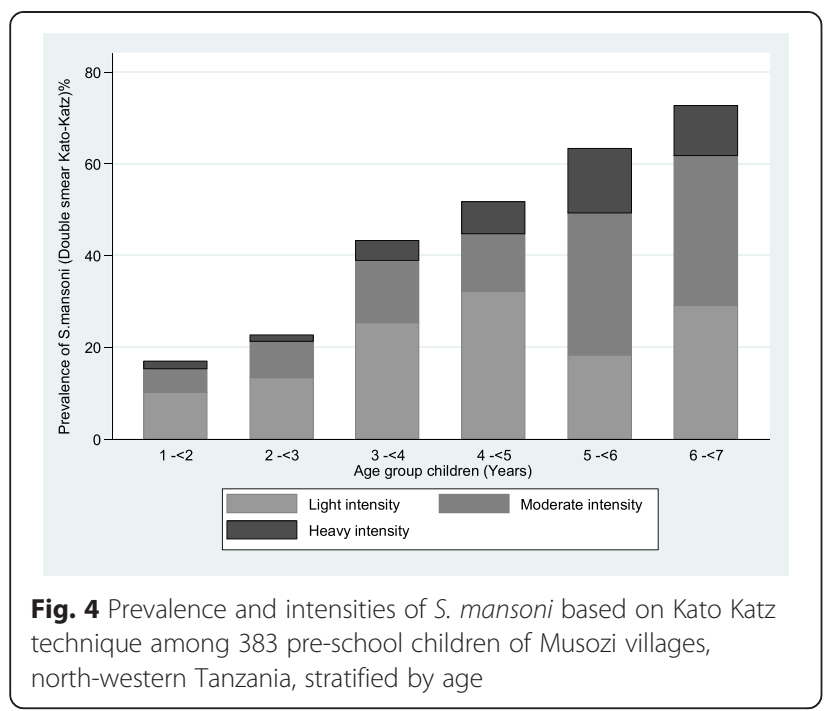

prevalence was observed to vary by age groups but not by sex. Infections with $S$. mansoni were predominantly light, but moderate intensity and heavy intensity infections were increasingly becoming common from the age of 3 years. The main identified risk factors associated with $S$. mansoni infection in PSC were history of water contact and living at a distance of less than $500 \mathrm{~m}$ from the lake water contact point. A bathing frequency at the lake of 4-7 days per week was associated with a heavier intensity of infection.

The prevalence of egg patent $S$. mansoni infection was 44.39 \% based on Kato-Katz, $45.85 \%$ based on CCA when trace was considered as negative and $80.05 \%$ on CCA when trace was considered as positive, of all the PSC who participated in the study. The prevalence estimates as determined by single stool double smear Kato-Katz and CCA with trace considered as negative (CCAt-) are broadly similar, however, the $35 \%$ increment in prevalence observed when trace is considered as positive (CCAt + ) is noted. It has been previously noted that when assessing the prevalence of $S$. mansoni using the CCA test alongside K$\mathrm{K}$, there is a higher 'true' prevalence with CCA than observed prevalence by $\mathrm{K}-\mathrm{K}$ rather than the CCA test yielding a high number of false positives [33]. The 'traces' for this study could partly be accounted for by the fact that in this population most of the children have light infection as noted by the Kato-Katz, therefore, it is possible that the traces can be explained by pre-patent infections.

The overall prevalence of $S$. mansoni observed in this study was higher than that reported on the same agegroup in Uganda on the shores of Lake Albert and Lake Victoria [45], in Usoma, Kenya [11] and in Ivory Coast [32] in West Africa. In addition, the overall geometrical mean in the present study was of moderate intensity and the majority of the children had light to moderate infection intensities. Only $6.53 \%$ of the study participants
Table 3 Prevalence of infection with S.mansoni in pre-school children in Musozi village in relation to demographic characteristics water contact patterns and distance from the lake water contact point

\begin{tabular}{|c|c|c|c|c|}
\hline Characteristic & No examined & $\begin{array}{l}\text { No infected } \\
\text { (Prevalence) }\end{array}$ & $\begin{array}{l}95 \% \text { confidence } \\
\text { interval }\end{array}$ & $\begin{array}{l}x 2 P \\
\text { value }\end{array}$ \\
\hline \multicolumn{5}{|l|}{$\overline{S e x}$} \\
\hline Female & 183 & 149 (81.42) & $75.73-87.11$ & \multirow[t]{2}{*}{$<0.73$} \\
\hline Male & 192 & 159 (82.81) & $77.43-88.20$ & \\
\hline \multicolumn{5}{|l|}{ Age (years) } \\
\hline $1-<2$ & 59 & $41(69.45)$ & 57.39-81.59 & \multirow[t]{6}{*}{$<0.00$} \\
\hline $2-<3$ & 75 & $51(68.00)$ & $57.19-78.80$ & \\
\hline $3-<4$ & 64 & 51 (79.69) & $69.56-89.82$ & \\
\hline $4-<5$ & 54 & $50(92.59)$ & 89.38-99.80 & \\
\hline $5-<6$ & 68 & 62 (91.18) & 84.26-98.09 & \\
\hline $6-<7$ & 55 & 53 (96.36) & $91.25-101.47$ & \\
\hline \multicolumn{5}{|l|}{ Go to the lake } \\
\hline No & 94 & $58(61.70)$ & $7.10-14.41$ & \multirow[t]{2}{*}{$<0.00$} \\
\hline Yes & 279 & 249 (89.25) & $85.58-92.90$ & \\
\hline \multicolumn{5}{|c|}{ Mode of contact } \\
\hline Never & 97 & $59(60.82)$ & $50.94-70.71$ & \multirow[t]{3}{*}{$<0.00$} \\
\hline Accompanied & 255 & $227(89.02)$ & $85.16-92.88$ & \\
\hline Alone & 21 & $21(100)$ & & \\
\hline \multicolumn{5}{|l|}{ Frequency } \\
\hline Never & 206 & $148(71.84)$ & $65.65-78.04$ & \multirow[t]{3}{*}{$<0.00$} \\
\hline Moderate & 59 & $51(86.44)$ & $77.44-95.44$ & \\
\hline High & 105 & $105(100)$ & & \\
\hline \multicolumn{5}{|l|}{ Who } \\
\hline Father & 7 & $6(85.71)$ & $50.76-120.67$ & \multirow[t]{5}{*}{$<0.68$} \\
\hline Mother & 89 & $85(95.51)$ & $91.11-99.89$ & \\
\hline Self & 10 & $10(100)$ & & \\
\hline Guardian & 6 & $6(100)$ & & \\
\hline Sibling & 49 & $46(95.03)$ & $86.92-100.83$ & \\
\hline \multicolumn{5}{|l|}{ Distance } \\
\hline$\leq 500 \mathrm{~m}$ & 146 & $117(80.14)$ & $73.58-86.68$ & \multirow[t]{2}{*}{$<0.26$} \\
\hline$>500 \mathrm{~m}$ & 154 & $131(85.06)$ & $79.37-90.75$ & \\
\hline
\end{tabular}

most of them aged three years and above presented with heavy intensities. The intensity of $S$. mansoni infection was observed to increase with an increase in the age of the study participants. The results of the present study also show that there was no significant difference in intensity of infection by sex. This is likely due to a similarity of PSC's water contact behaviour and parents' or guardians' behaviour towards their children's water contact between the two sexes. As they grow older this similarity is lost as their behaviour towards water contact changes. This is affirmed by higher prevalence and 
Table 4 The factors associated with the prevalence of infection in preschool children in Musozi village Ukerewe district

\begin{tabular}{|c|c|c|c|c|c|c|}
\hline \multirow[t]{2}{*}{ Characteristic } & \multicolumn{3}{|c|}{ Bivariate } & \multicolumn{3}{|c|}{ Multivariate } \\
\hline & $\overline{\mathrm{OR}}$ & $95 \% \mathrm{Cl}$ & $P$-value & $\overline{\mathrm{AOR}}$ & $95 \% \mathrm{Cl}$ & $P$-value \\
\hline \multicolumn{7}{|l|}{ Sex } \\
\hline Female & 1 & & & 1 & & \\
\hline Male & 1.09 & $0.65-1.87$ & 0.73 & 1.02 & $0.51-2.03$ & 0.95 \\
\hline \multicolumn{7}{|l|}{ Age (years) } \\
\hline $1-<2$ & 1 & & & 1 & & \\
\hline $2-<3$ & 0.93 & $0.45-1.94$ & 0.85 & 0.64 & $0.26-1.61$ & 0.35 \\
\hline $3-<4$ & 1.72 & $0.76-3.92$ & 0.20 & 1.11 & $0.40-3.10$ & 0.83 \\
\hline $4-<5$ & 5.49 & $1.72-17.49$ & 0.00 & 2.56 & $0.61-10.71$ & 0.20 \\
\hline $5-<6$ & 4.54 & $1.66-12.78$ & 0.00 & 1.32 & $0.37-4.62$ & 0.66 \\
\hline $6-<7$ & 11.63 & $2.55-53.01$ & 0.00 & 2.28 & $0.41-12.46$ & 0.34 \\
\hline \multicolumn{7}{|l|}{ Go to the lake } \\
\hline No & 1 & & & 1 & & \\
\hline Yes & 5.15 & $2.94-9.04$ & 0.00 & 2.31 & $1.06-5.01$ & 0.03 \\
\hline \multicolumn{7}{|l|}{ Mode of contact } \\
\hline Never & 1 & & & & & \\
\hline Accompanied & 5.22 & $2.96-9.20$ & 0.00 & & & \\
\hline \multicolumn{7}{|l|}{ Alone } \\
\hline \multicolumn{7}{|l|}{ Frequency } \\
\hline Never & 1 & & & 1 & & \\
\hline Moderate & 2.50 & $1.11-5.58$ & 0.03 & 1.54 & $0.54-4.37$ & 0.409 \\
\hline \multicolumn{7}{|l|}{ High } \\
\hline \multicolumn{7}{|l|}{ Who } \\
\hline Father & 1 & & & & & \\
\hline Mother & 3.54 & $0.34-36.8$ & 0.29 & & & \\
\hline \multicolumn{7}{|l|}{ Self } \\
\hline \multicolumn{7}{|l|}{ Guardian } \\
\hline Sibling & 2.56 & $0.22-28.67$ & 0.45 & & & \\
\hline \multicolumn{7}{|l|}{ Distance } \\
\hline$>500 \mathrm{~m}$ & 1 & & & 1 & & \\
\hline$\leq 500 \mathrm{~m}$ & 1.59 & $0.84-2.98$ & 0.14 & 2.09 & $1.05-4.14$ & 0.034 \\
\hline
\end{tabular}

$O R$ odds ratio, $A O R$ adjusted odds ratio, $\mathrm{Cl}$ confidence interval

intensity of S. mansoni in males than females in school children. Similar findings were reported in Ivory Coast [32]. In comparison to studies conducted on the shores of the Lake Victoria in Uganda [45] and West Africa [32], the prevalence of heavy infection among PSC was higher in the present study. This could be due to the behavior of this population group especially those living $500 \mathrm{~m}$ from the lake and their repeated contact with contaminated water and lack of safe water for bathing and improved sanitation facilities. Adult individuals living in this particular setting have been repeatedly reported to be highly infected with $S$. mansoni and carry the highest intensities of infection [46, 47]. Increased
Table 5 The relationship between the geometric mean of intensity of infection (GMI) in preschool children in Musozi village in Ukerewe North Western and the demographic characteristics

\begin{tabular}{|c|c|c|c|c|}
\hline Characteristic & No infected & $\mathrm{GMI}$ & $95 \% \mathrm{Cl}$ & $P$-values \\
\hline \multicolumn{5}{|l|}{ Sex } \\
\hline Male & 80 & 101.9 & $79.2-131.4$ & \multirow[t]{2}{*}{$<0.41^{a}$} \\
\hline Female & 90 & 118.9 & $93.7-150.8$ & \\
\hline \multicolumn{5}{|l|}{ Age } \\
\hline $1-<2$ & 10 & 74.7 & 29.4-189.6 & \multirow[t]{6}{*}{$<0.00^{b}$} \\
\hline $2-<3$ & 17 & 73.5 & $36.9-146.4$ & \\
\hline $3-<4$ & $29^{\prime}$ & 79.5 & $54.6-115.8$ & \\
\hline $4-<5$ & 29 & 91.9 & $60.1-140.4$ & \\
\hline $5-<6$ & 45 & 175.8 & $128.9-235.7$ & \\
\hline $6-<7$ & 40 & 125.3 & $88.6-177.2$ & \\
\hline \multicolumn{5}{|l|}{ Go to the lake } \\
\hline No & 21 & 77.6 & $45.2-133.3$ & \multirow[t]{2}{*}{$<0.00^{\mathrm{a}}$} \\
\hline Yes & 149 & 116.3 & $97-139.4$ & \\
\hline \multicolumn{5}{|l|}{ Mode of contact } \\
\hline Never & 21 & 77.6 & $45.2-133.3$ & \multirow[t]{3}{*}{$<0.00^{b}$} \\
\hline Accompanied & 136 & 109.7 & $90.6-132.8$ & \\
\hline Alone & 13 & 213.6 & $124.4-366.6$ & \\
\hline \multicolumn{5}{|l|}{ Frequency } \\
\hline Never & 57 & 75.7 & $55.2-104$ & \multirow[t]{3}{*}{$<0.00^{b}$} \\
\hline Moderate (1-3) & 33 & 93.5 & 66.9-130.5 & \\
\hline High (4-7) & 76 & 117.9 & 117.9-193.8 & \\
\hline \multicolumn{5}{|l|}{ Who } \\
\hline Father & 5 & 101 & $46.3-220.5$ & \\
\hline Mother & 34 & 133.7 & $92-194.3$ & \\
\hline Self & 62 & 122.7 & $93.3-161.5$ & \\
\hline Guardian & 6 & 350.7 & 137.9-892 & \\
\hline Sibling & 3 & 122 & 7.6-1967 & \\
\hline \multicolumn{5}{|l|}{ Distance } \\
\hline$>500 \mathrm{~m}$ & 70 & 123.1 & $92.8-163.1$ & \multirow[t]{2}{*}{$<0.28^{\mathrm{a}}$} \\
\hline$\leq 500 \mathrm{~m}$ & 71 & 108.9 & $83-142.9$ & \\
\hline
\end{tabular}

Determined by $T$-test

betermined by ANOVA

water contact activities such as fishing, bathing and farming were associated with an increased risk of being infected with $S$. mansoni in the adult population [48].

One remarkable observation was that heavy infections were more common from the age of three years onwards where the prevalence was $4.4 \%$ in 3-year-olds and $10.9 \%$ in 6-year-olds. This has shown that young children can have heavy infections even at an age as young as 3 years old. It has been depicted that the heavier the infection the more severe the morbidity; however, even light egg patent infections $[49,50]$ and sub-egg patent 
Table 6 The factors associated with log transformed egg counts in preschool children in Musozi village Ukerewe district North Western Tanzania

\begin{tabular}{|c|c|c|c|c|c|c|}
\hline \multirow[t]{2}{*}{ Characteristic } & \multicolumn{3}{|c|}{ Bivariate } & \multicolumn{3}{|c|}{ Multivariate } \\
\hline & $\mathrm{OR}$ & $95 \% \mathrm{Cl}$ & $P$-value & $\mathrm{AOR}$ & $95 \% \mathrm{Cl}$ & $P$-value \\
\hline \multicolumn{7}{|l|}{ Sex } \\
\hline Female & 1 & & & 1 & & \\
\hline Male & 1.16 & $0.83-1.64$ & 0.38 & 1.17 & $0.83-1.65$ & 0.13 \\
\hline \multicolumn{7}{|l|}{ Age (years) } \\
\hline $1-<2$ & 1 & & & & & \\
\hline $2-<3$ & 0.98 & $0.41-2.34$ & 0.97 & 0.94 & $0.39-2.24$ & 0.88 \\
\hline $3-<4$ & 1.06 & $0.47-2.36$ & 0.87 & 0.98 & $0.43-2.26$ & 0.97 \\
\hline $4-<5$ & 1.23 & $0.55-2.73$ & 0.60 & 1.10 & $0.47-2.56$ & 0.81 \\
\hline $5-<6$ & 2.35 & $1.10-5.03$ & 0.02 & 2.05 & $0.90-4.69$ & 0.08 \\
\hline $6-<7$ & 1.67 & $0.78-3.62$ & 0.19 & 1.49 & $0.65-3.41$ & 0.33 \\
\hline \multicolumn{7}{|l|}{ Go to the lake } \\
\hline No & 1 & & & 1 & & \\
\hline Yes & 1.49 & $0.89-2.51$ & 0.12 & 0.74 & $0.39-1.41$ & 0.36 \\
\hline \multicolumn{7}{|l|}{ Mode of contact } \\
\hline Never & 1 & & & & & \\
\hline Accompanied & 1.41 & $0.84-2.37$ & 0.19 & & & \\
\hline Alone & 2.75 & $1.26-6.00$ & 0.01 & & & \\
\hline \multicolumn{7}{|l|}{ Frequency } \\
\hline Never & 1 & & & 1 & & \\
\hline Moderate & 1.23 & $0.76-1.98$ & 0.38 & 1.30 & $0.77-2.19$ & 0.30 \\
\hline High & 1.99 & $1.36-2.91$ & 0.00 & 1.84 & $1.18-2.86$ & 0.00 \\
\hline \multicolumn{7}{|l|}{ Who } \\
\hline Father & 1 & & & & & \\
\hline Mother & 1.20 & $0.26-5.57$ & 0.80 & & & \\
\hline Self & 1.21 & $0.46-3.21$ & 0.69 & & & \\
\hline Guardian & 1.32 & $0.48-3.60$ & 0.58 & & & \\
\hline Sibling & 3.47 & $0.97-12.34$ & 0.05 & & & \\
\hline \multicolumn{7}{|l|}{ Distance } \\
\hline$>500 \mathrm{~m}$ & 1 & & & & & \\
\hline$\leq 500 \mathrm{~m}$ & 0.88 & $0.60-1.30$ & 0.53 & & & \\
\hline
\end{tabular}

infections are considered to be detrimental to wellbeing, especially in younger children $[51,52]$. It is therefore important to focus on these children because they are set to suffer significant morbid effects as explained by King and Dangerfield-Cha [4] and mostly because it can take up to 3 years before they are treated.

Our study also examined the risk factors associated with $S$. mansoni infection in PSC, whereby the results show a significant association between the history of a visit to the lake and the infection with $S$. mansoni in this age group. Those who reported going to the lake had twice the odds of being infected with S. mansoni infection. This is supported by an observation made in western Kenya where reported water contact with the lake was associated with the infection with $S$. mansoni [53]. The distance from the water contact point was strongly associated with the infection with schistosomiasis, whereby, those who lived $<500 \mathrm{~m}$ from the lake water contact point were at twice the odds of being infected with $S$. mansoni infection. It has been demonstrated that for this age group, the distance from the water point and the history of visiting the lake were significant factors for schistosomiasis infection. This is particularly important as lake water, which is the source of water for bathing and other domestic uses including drinking for some of the villagers, was continuously contaminated with S.mansoni eggs from the poor sanitation practice of defaecating in the lake water. This corroborates studies carried out in Western Kenya [53] and Tanzania [6] which found that the prevalence of infection decreases with the increase of the distance from the lake water shore. A history of a high frequency of bathing in lake water, (4-7 days) per week, was shown to be associated with a heavy $S$. mansoni infection where those who had high bathing frequency in lake water were at a 1.8 higher odds of heavy infection. Our present study is subject to limitation. The findings of this study only apply to the geographical setting where the study was undertaken and cannot be generalised to other geographical settings. The temporal relationship between some of the risk factors and the study outcomes could not be assessed due to the study design.

\section{Conclusions}

In conclusion, this study has demonstrated that the prevalence of S. mansoni in PSC in Musozi village in Ukerewe based on KK and CCAt- was moderate and high on CCAt+. It has also shown that moderate and heavy infections are common from the age of three years onwards. It is, therefore, important to consider including children of 3 years in PZQ-MDA programmes because they are set to suffer the significant morbid effects of chronic schistosomiasis. This study has also shown that going to the lake and living at a distance of $\leq 500 \mathrm{~m}$ to the lake were associated with a significant risk of being infected. It is important to provide health education for behaviour change to avoid contaminated water for the whole village community. Provision of safe water for the whole community for all domestic uses including bathing is also necessary. As efforts to develop and evaluate paediatric formulations of Praziquantel are underway, more studies to quantify the prevalence of $S$. mansoni infection in that particular age group should be carried out at the country level. Further investigation to quantify the morbidity due to intestinal schistosomiasis in this age group is recommended. 


\section{Competing interests}

The authors declare that they have no competing interests.

\section{Authors' contributions}

DMR, RW, GMM were involved in the study design. DMR and HDM carried out data collection, analysis and manuscript preparation. DM critically reviewed the manuscript and the interpretation of the results. All authors read and approved the final manuscript.

\section{Acknowledgment}

We appreciate the parents and children who participated in this study and the technical work of Mr. Philbert Kashangaki and Mr. Petro Mnyeshi of the National Institute for Medical Research. We acknowledge the financial support from the Catholic University of Health and Allied Sciences, Mwanza, Tanzania

HDM is supported by the Training Health Researchers into Vocational Excellence in East Africa (THRiVE) Programme funded by The Wellcome Trust, grant number 087540 and by Tropical Disease Research, the Special Programme for Research and Training in Tropical Diseases, co-sponsored by UNICEF, UNDP, the World Bank and WHO, we acknowledge their support.

\section{Author details}

${ }^{1}$ Department of Medical Parasitology and Entomology, School of Medicine, Catholic University of Health and Allied Sciences, P.O. Box 1464, Mwanza, Tanzania. ${ }^{2}$ Department of Zoology, Jomo Kenyatta University of Agriculture and Technology, P.O. Box 62000-00200, Nairobi, Kenya. ${ }^{3}$ Institute of Tropical Medicine and Infectious Diseases (ITROMID), Jomo Kenyatta University of Agriculture and Technology, P.O. Box 62000-00200, Nairobi, Kenya. ${ }^{4}$ Centre for Biotechnology Research and Development, Kenya Medical Research Institute (KEMRI), PO Box 54840-00200, Nairobi, Kenya.

Received: 1 July 2015 Accepted: 9 July 2015

Published online: 16 July 2015

\section{References}

1. Hotez PJ, Kamath A. Neglected tropical diseases in sub-saharan Africa: review of their prevalence, distribution, and disease burden. PLoS Negl Trop Dis. 2009;3(8):e412.

2. van der Werf MJ, de Vlas SJ, Brooker S, Looman CW, Nagelkerke NJ, Habbema JD, et al. Quantification of clinical morbidity associated with schistosome infection in sub-Saharan Africa. Acta Trop. 2003;86(2-3):125-39.

3. King CH, Dickman K, Tisch DJ. Reassessment of the cost of chronic helmintic infection: a meta-analysis of disability-related outcomes in endemic schistosomiasis. Lancet. 2005;365(9470):1561-9.

4. King $\mathrm{CH}$, Dangerfield-Cha M. The unacknowledged impact of chronic schistosomiasis. Chronic IIIn. 2008:4(1):65-79.

5. Koukounari A, Fenwick A, Whawell S, Kabatereine NB, Kazibwe F, Tukahebwa EM, et al. Morbidity indicators of Schistosoma mansoni: relationship between infection and anemia in Ugandan schoolchildren before and after praziquantel and albendazole chemotherapy. Am J Trop Med Hyg. 2006;75(2):278-86.

6. Lwambo NJ, Siza JE, Brooker S, Bundy DA, Guyatt H. Patterns of concurrent hookworm infection and schistosomiasis in schoolchildren in Tanzania. Trans R Soc Trop Med Hyg. 1999;93(5):497-502.

7. Mazigo HD, Waihenya R, Lwambo NJ, Mnyone LL, Mahande AM, Seni J, et al. Co-infections with Plasmodium falciparum, Schistosoma mansoni and intestinal helminths among schoolchildren in endemic areas of northwestern Tanzania. Parasites Vectors. 2010;3:44.

8. Kinung'hi SM, Magnussen P, Kaatano GM, Kishamawe C, Vennervald BJ. Malaria and helminth co-infections in school and preschool children: a cross-sectional study in Magu district, north-western Tanzania. PLoS One. 2014;9(1):e86510.

9. National bureau of statistics (NBS) [Tanzania], ICF Macro. Tanzania demographic and health survey 2010. Dar es Salaam, Tanzania: National bureau of statistics (NBS) [Tanzania], ICF Macro; 2011.

10. Sousa-Figueiredo JC, Pleasant J, Day M, Betson M, Rollinson D, Montresor A, et al. Treatment of intestinal schistosomiasis in Ugandan preschool children: best diagnosis, treatment efficacy and side-effects, and an extended praziquantel dosing pole. Int Health. 2010;2(2):103-13.
11. Verani JR, Abudho B, Montgomery SP, Mwinzi PN, Shane HL, Butler SE, et al. Schistosomiasis among young children in Usoma, Kenya. Am J Trop Med Hyg. 2011;84(5):787-91.

12. Smith FM. Bilharziasis in the African infant and child in the Mtoko District, Southern Rhodesia. Cent Afr J Med. 1958;4(7):287-8.

13. Perel Y, Sellin B, Perel C, Arnold P, Mouchet F. Use of urine collectors for infants from 0 to 4 years of age in a mass survey of urinary schistosomiasis in Niger. Med Trop (Mars). 1985;45(4):429-33.

14. Kabatereine NB, Brooker S, Koukounari A, Kazibwe F, Tukahebwa EM, Fleming FM, et al. Impact of a national helminth control programme on infection and morbidity in Ugandan schoolchildren. Bull World Health Organ. 2007;85(2):91-9.

15. Bosompem KM, Bentum IA, Otchere J, Anyan WK, Brown CA, Osada Y, et al. Infant schistosomiasis in Ghana: a survey in an irrigation community. Trop Med Int Health. 2004;9(8):917-22.

16. Odogwu SE, Ramamurthy NK, Kabatereine NB, Kazibwe F, Tukahebwa E, Webster JP, et al. Schistosoma mansoni in infants (aged $<3$ years) along the Ugandan shoreline of Lake Victoria. Ann Trop Med Parasitol. 2006;100(4):315-26.

17. Mafiana CF, Ekpo UF, Ojo DA. Urinary schistosomiasis in preschool children in settlements around Oyan Reservoir in Ogun State, Nigeria: implications for control. Trop Med Int Health. 2003;8(1):78-82.

18. Stothard JR, Gabrielli AF. Schistosomiasis in African infants and preschool children: to treat or not to treat? Trends Parasitol. 2007;23(3):83-6.

19. Opara KN, Udoidung NI, Ukpong IG. Genitourinary schistosomiasis among pre-primary schoolchildren in a rural community within the Cross River Basin, Nigeria. J Helminthol. 2007;81(4):393-7.

20. Ekpo UF, Laja-Deile A, Oluwole AS, Sam-Wobo SO, Mafiana CF. Urinary schistosomiasis among preschool children in a rural community near Abeokuta, Nigeria. Parasites Vectors. 2010;3:58.

21. Jordan P, Webbe G. Human schistosomiasis. In: Human schistosomiasis. 1969.

22. van Lieshout L, Polderman AM, Deelder AM. Immunodiagnosis of schistosomiasis by determination of the circulating antigens CAA and CCA, in particular in individuals with recent or light infections. Acta Trop. 2000;77(1):69-80

23. Berhe N, Medhin G, Erko B, Smith T, Gedamu S, Bereded D, et al. Variations in helminth faecal egg counts in Kato-Katz thick smears and their implications in assessing infection status with Schistosoma mansoni. Acta Trop. 2004;92(3):205-12.

24. Bergquist $\mathrm{R}$, Johansen MV, Utzinger J. Diagnostic dilemmas in helminthology: what tools to use and when? Trends Parasitol. 2009;25(4):151-6.

25. Johansen MV, Sithithaworn P, Bergquist R, Utzinger J. Towards improved diagnosis of zoonotic trematode infections in Southeast Asia. Adv Parasitol. 2010;73:171-95.

26. Utzinger J, Booth M, N'Goran EK, Muller I, Tanner M, Lengeler C. Relative contribution of day-to-day and intra-specimen variation in faecal egg counts of Schistosoma mansoni before and after treatment with praziquantel. Parasitology. 2001;122(Pt 5):537-44.

27. Booth M, Vounatsou P, N'Goran EK, Tanner M, Utzinger J. The influence of sampling effort and the performance of the Kato-Katz technique in diagnosing Schistosoma mansoni and hookworm co-infections in rural Cote d'Ivoire. Parasitology. 2003;127(Pt 6):525-31.

28. Yu JM, de Vlas SJ, Jiang QW, Gryseels B. Comparison of the Kato-Katz technique, hatching test and indirect hemagglutination assay $(\mathrm{IHA})$ for the diagnosis of Schistosoma japonicum infection in China. Parasitol Int. 2007;56(1):45-9.

29. Lin DD, Liu JX, Liu YM, Hu F, Zhang YY, Xu JM, et al. Routine Kato-Katz technique underestimates the prevalence of Schistosoma japonicum: a case study in an endemic area of the People's Republic of China. Parasitol Int. 2008;57(3):281-6.

30. Legesse M, Erko B. Field-based evaluation of a reagent strip test for diagnosis of Schistosoma mansoni by detecting circulating cathodic antigen in urine before and after chemotherapy. Trans R Soc Trop Med Hyg. 2007;101(7):668-73.

31. Ashton RA, Stewart BT, Petty N, Lado M, Finn T, Brooker S, et al. Accuracy of circulating cathodic antigen tests for rapid mapping of Schistosoma mansoni and S. haematobium infections in Southern Sudan. Trop Med Int Health. 2011;16(9):1099-103.

32. Coulibaly JT, N'Gbesso YK, N'Guessan NA, Winkler MS, Utzinger J, N'Goran EK. Epidemiology of schistosomiasis in two high-risk communities of south 
Cote d'Ivoire with particular emphasis on pre-school-aged children. Am J Trop Med Hyg. 2013;89(1):32-41.

33. Navaratnam AM, Mutumba-Nakalembe MJ, Stothard JR, Kabatereine NB, Fenwick A, Sousa-Figueiredo JC. Notes on the use of urine-CCA dipsticks for detection of intestinal schistosomiasis in preschool children. Trans R Soc Trop Med Hyg. 2012;106(10):619-22

34. Standley CJ, Lwambo NJ, Lange CN, Kariuki HC, Adriko M, Stothard JR. Performance of circulating cathodic antigen (CCA) urine-dipsticks for rapid detection of intestinal schistosomiasis in schoolchildren from shoreline communities of Lake Victoria. Parasites Vectors. 2010;3(1):7.

35. Stothard JR, Kabatereine NB, Tukahebwa EM, Kazibwe F, Rollinson D, Mathieson W, et al. Use of circulating cathodic antigen (CCA) dipsticks for detection of intestinal and urinary schistosomiasis. Acta Trop. 2006;97(2):219-28.

36. Shane $\mathrm{HL}$, Verani JR, Abudho B, Montgomery SP, Blackstock AJ, Mwinzi PN, et al. Evaluation of urine CCA assays for detection of Schistosoma mansoni infection in Western Kenya. PLoS Negl Trop Dis. 2011;5(1):e951.

37. Garba A, Barkire N, Djibo A, Lamine MS, Sofo B, Gouvras AN, et al. Schistosomiasis in infants and preschool-aged children: Infection in a single Schistosoma haematobium and a mixed S. haematobium-S. mansoni foci of Niger. Acta Trop. 2010;115(3):212-9.

38. Rollinson D, Knopp S, Levitz S, Stothard JR, Tchuem Tchuente LA, Garba A, et al. Time to set the agenda for schistosomiasis elimination. Acta Trop. 2013;128(2):423-40.

39. National bureau of statistics. 2012 census database. 2014th ed. Tanzania: National bureau of statistics; 2012.

40. Katz N, Chaves A, Pellegrino J. A simple device for quantitative stool thicksmear technique in Schistosomiasis mansoni. Revista Instituto de Medicine Tropica Sao Paulo. 1972;14(6):397-400.

41. Barreto ML, Smith D, Sleigh AC. Implications of feacal egg count variation when using the Kato Katz method to assess S. mansoni infections. Trans R Soc Trop Med Hyg. 1990;84:554-5.

42. Van Dam G, Wichers J, Ferreira TF, Ghati D, Van Amerongen A, Deelder A. Diagnosis of schistosomiasis by reagent strip test for detection of circulating cathodic antigen. J Clin Microbiol. 2004;42(12):5458-61.

43. WHO. Basic laboratory methods in medical parasitology. 1991

44. WHO. Prevention and control of schistosomiasis and soil-transmitted helminthiasis. World Health Organ Tech Rep Ser. 2002;912:i.

45. Sousa-Figueiredo JC, Betson M, Kabatereine NB, Stothard JR. The urine circulating cathodic antigen (CCA) dipstick: a valid substitute for microscopy for mapping and point-of-care diagnosis of intestinal schistosomiasis. PLoS Negl Trop Dis. 2013;7(1):e2008.

46. Malenganisho WL, Magnussen P, Friis H, Siza J, Kaatano G, Temu M, et al. Schistosoma mansoni morbidity among adults in two villages along Lake Victoria shores in Mwanza District, Tanzania. Trans R Soc Trop Med Hyg. 2008;102(6):532-41.

47. Kardorff R, Gabone RM, Mugashe C, Obiga D, Ramarokoto CE, Mahlert C, et al. Schistosoma mansoni-related morbidity on Ukerewe Island, Tanzania: clinical, ultrasonographical and biochemical parameters. Trop Med Int Health. 1997;2(3):230-9.

48. Kloos H, Gazzinelli A, Van Zuyle P. Microgeographical patterns of schistosomiasis and water contact behavior; examples from Africa and Brazil. Mem Inst Oswaldo Cruz. 1998;93 Suppl 1:37-50.

49. Boisier $P$, Ramarokoto CE, Ravoniarimbinina $P$, Rabarijaona L, Ravaoalimalala VE. Geographic differences in hepatosplenic complications of schistosomiasis mansoni and explanatory factors of morbidity. Trop Med Int Health. 2001;6(9):699-706.

50. Berhe N, Myrvang B, Gundersen SG. Intensity of Schistosoma mansoni, hepatitis B, age, and sex predict levels of hepatic periportal thickening/ fibrosis (PPT/F): a large-scale community-based study in Ethiopia. Am J Trop Med Hyg. 2007;77(6):1079-86.

51. Gurarie D, Wang X, Bustinduy AL, King CH. Modeling the effect of chronic schistosomiasis on childhood development and the potential for catch-up growth with different drug treatment strategies promoted for control of endemic schistosomiasis. Am J Trop Med Hyg. 2011;84(5):773-81.
52. Terer CC, Bustinduy AL, Magtanong RV, Muhoho N, Mungai PL, Muchiri EM, et al. Evaluation of the health-related quality of life of children in Schistosoma haematobium-endemic communities in Kenya: a crosssectional study. PLoS Negl Trop Dis. 2013;7(3):e2106.

53. Handzel T, Karanja DM, Addiss DG, Hightower AW, Rosen DH, Colley DG, et al. Geographic distribution of schistosomiasis and soil-transmitted helminths in Western Kenya: implications for anthelminthic mass treatment. Am J Trop Med Hyg. 2003;69(3):318-23.

\section{Submit your next manuscript to BioMed Central and take full advantage of:}

- Convenient online submission

- Thorough peer review

- No space constraints or color figure charges

- Immediate publication on acceptance

- Inclusion in PubMed, CAS, Scopus and Google Scholar

- Research which is freely available for redistribution 